\title{
An Integrated, Real-time Approach to Process Control System Design Education
}

\author{
Brent Young* and William Svrcek \\ Department of Chemical and Petroleum Engineering, \\ University of Calgary, 2500 University Drive NW, Calgary, Alberta T2N 1N4 \\ *E-mail: byoung@ucalgary.ca
}

\begin{abstract}
Throughout the chemical and process industries, ever more emphasis is being placed upon extracting increasingly greater value from plant equipment, with substantial interest in energy efficiency and responsible environmental stewardship. Improved process control is almost unique in its ability to deliver substantial operational efficiency and environmental improvements with relatively little additional capital investment. As such, process control has become one of the most sought after skills within the chemical and process industries. Industry needs graduates that are educated in the latest and most relevant skills. Industry practitioners rely heavily on commercially available process simulation tools and hands on, time domain based control strategy development techniques, e.g. [12].

This paper describes an integrated, real-time approach to the education of undergraduate chemical engineering students in process control system design [3-4]. The real-time approach to process control system design education integrates introductory process control education and industrial practice. The approach focuses on the more applied and practical time domain based techniques derived from modern process simulation. The use of computers is a central theme to the approach, and their use in simulations and the software is carefully introduced. The students gain a thorough understanding of instrumentation, process design versus controllability trade offs, control loop configurations and tuning, practical techniques for the control of unit operations and basic plant-wide control.

This integrated, real-time approach to the education of undergraduate chemical engineering students in process dynamics and control has been
\end{abstract}

taught as a capstone subject at the University of Calgary since 1997 using active, "hands on" or resource based learning [5-6]. A small number of lectures at the beginning of the course are advocated from a learning perspective to motivate students rather than to simply transmit information. A majority of "hands on" tutorial and / or simulation sessions are recommended on case studies, workshops or projects facilitated by the instructors [7]. The approach is illustrated by examples from this capstone course.

\section{Introduction}

Chemical processes are characterized by high degrees of non-linearity, process interactions, and substantial dead time. Due to these non-idealities, chemical process control needs to be addressed with a multivariable and plant-wide view. In an ideal world, the student chemical engineer would have a "virtual plant" on which to experiment. This plant would capture all of the important nonidealities the real world imposes, and would allow the student engineer to readily test even the most outlandish of control structures with impunity.

Early attempts to realize this "ideal world" date back to the seventies and eighties (Svrcek et al., [8]) when dynamic simulators such as DYFLO (Franks, [9]), DYNSYS (Ausain, [10]) or SPEEDUP (Perkins, [11]) first became available for the solution of the non-linear differential equations describing process dynamics. However, the hardware was slow at this time, and the software was impractical for students to learn and implement in a reasonable time frame. There was effectively no user interface in that the graphics were poor and the programs were run batch-wise.

However, in today's "simulation-rich" environment (Svrcek et al., [8]), the right combination of hardware and software is available (and, it is important to note, affordable for 
educational institutions) to implement a "real time" approach to process control education (Svrcek et al., [7]). The hardware and software, such as HYSYS [12], Aspen Dynamics [13] and MATLAB [14], is now fast and easy to use. Simple, complex and/or user defined process modules are available and it is now facile to do "what-if" studies, multiloop and plant wide control simulations. The software user interface is now graphical and interactive and the software can be painlessly run on a personal computer. In short, the "virtual plant" has arrived.

This real time approach also very naturally lends itself to active, "hands on" or resource based learning (Litster et al., [5]; Clough, [6]). From a learning perspective, a small number of lectures at the beginning of the course to motivate students rather than to transmit information and a majority of "hands on" simulation tutorial sessions on case study projects or workshops facilitated by the instructors is advocated (Svrcek et al., [7]).

It is also important to note that while computer simulations provide generally favourable experiences, real experiments are still necessary and desirable (White and Bodner, [15]). Real experiments such as a cascade of tanks and a heat exchanger in a pilot plant laboratory allow students to perform process identification exercises on real plant and tune real controllers. So that the student understands the underlying "physics" of process control, modeling exercises that require the student to write the describing differential equations and solve them numerically using MATLAB should also associated with these laboratory plant experiences.

\section{Integrated, Real-time Workshops}

The set of workshops are prefaced by a statement of the course philosophy, "learning through doing" that was perhaps best articulated in the following statement by Benjamin Franklin (circa. 1732-57):

"Tell me and I forget,

Show me and I may remember,

Involve me and I understand"

Each of the workshops is structured in the following similar manner. First a strong recommendation to read the appropriate theory from the associated text is made and also briefly summarised. The key learning objectives are then listed for the student's information and reference for study. Finally the various tasks that the student must complete are outlined along with questions for answer and discussion.
It is recommended that one-week be assigned for completion of each of the workshops 1 through to 6 and two weeks each for the completion of workshops 7 and 8. It is also recommended that three separate tutorial hours in a conventional classroom be assigned for dealing with questions on the workshops and related theory. This should be in addition to two three-hour computer laboratories on the workshops facilitated by tutors plus unconstrained access to the computer laboratories outside of class times.

With the exception of the first workshop, which does not require a report, the workshops should be assessed by a short word-processed report in hardcopy of less than six pages. A diskette with the simulator files that were used to generate the findings of the report is also mandatory.

\subsection{Workshop 1 - Learning Through Doing}

This philosophy is articulated by the first "workshop" which describes the key learning objectives, course coverage, pre-requisites, study material, organisation and total course objectives.

As a first practical task the students must learn how to use the dynamic simulator of choice employed for the workshops. Students at the University of Calgary already have familiarity with the steady state features of HYSYS through the first semester of their capstone design course. They therefore learn to use the dynamic features of HYSYS in a one-week block "hands-on" tutorial course in a computer laboratory prior to the start of semester. A similar "hands-on" introduction is recommended for Aspen Dynamics or MATLAB.

\subsection{Workshop 2 - Feedback Control Loop \\ Concepts}

Capacity dominated process behaviour can be best studied using a very common process element, namely the surge tank or separator. The level response of a single tank to changes in inlet flow and temperature is first studied for linear and nonlinear outlet valves. The temperature response of the tank with steam heating as shown schematically in Figure 1 was also studied and a plug flow pipe element is also added to simulate dead time.

\subsection{Workshop 3 - Process Capacity and Dead Time}

This workshop illustrates the effect on the process response of the three key process dynamic parameters: process gain, time constant and dead time. The impact that capacitance or lag has on these process parameters is also explored. The process parameters are identified for an illustrative capacity dominated process and a process 
containing dead time, Figures 2 and 3, respectively. The process attenuation of a sinusoidal temperature disturbance input is studied for three tank levels.

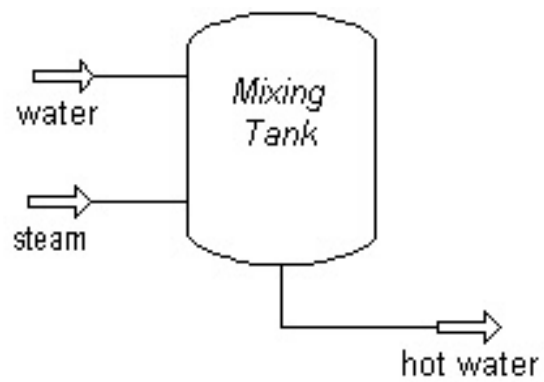

Fig. 1. Mixing Tank Process.

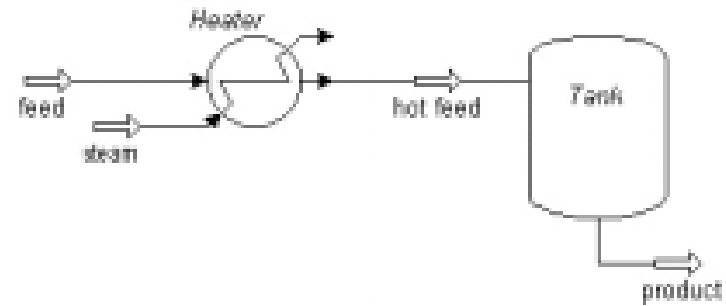

Fig 2. Illustrative Capacity-Dominated Process.

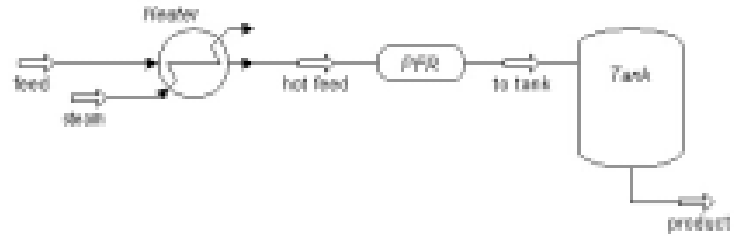

Fig 3. Illustrative Process Containing Dead Time.

\subsection{Workshop 4 - Feedback Control}

The basic understanding of the processes in workshop 3 (Figures 2 and 3 ) is applied to control the process responses via feedback control. The effect of dead time and capacity on P, PI and PID control of the steam duty stream is examined through looking at the response to set point and disturbance changes. Averaging control of the tank level is also studied.

\subsection{Workshop 5 - Controller Tuning for Capacity and Dead Time Processes}

This workshop involves the determination of the appropriate parameters for a PI controller that is controlling a capacitive process with significant dead time. The Ziegler and Nichols [16] closed loop-tuning technique and the auto-tune variation tuning technique of Åström and Hagglund [17] are employed for set point and disturbance tuning, and the results compared. The controller contributions to attenuation are also determined and compared to the results from workshop 3 .

\subsection{Workshop 6-Topics in Advanced Classical Control}

This workshop shows how the response of feedback control loops can be improved through the use of other control methods. These other methods include measuring common disturbances and taking action before they effect the controlled variable (feedforward control) and using a faster loop to decrease the response time of a system with a large time constant (cascade control). The conditions are determined that are necessary for feedforward or cascade to be useful and the parameters that reduce the effectiveness of these control methods. The same simple heating system of workshops 3, 4 and 5, Figure 3, is used to illustrate these concepts.

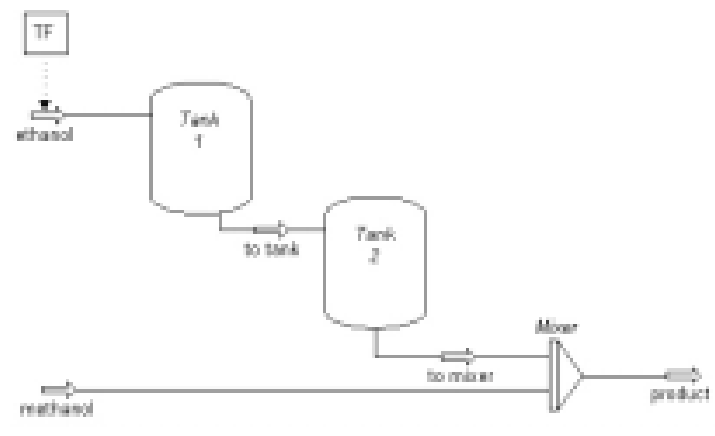

Fig. 4. Example Process for Ratio Control.

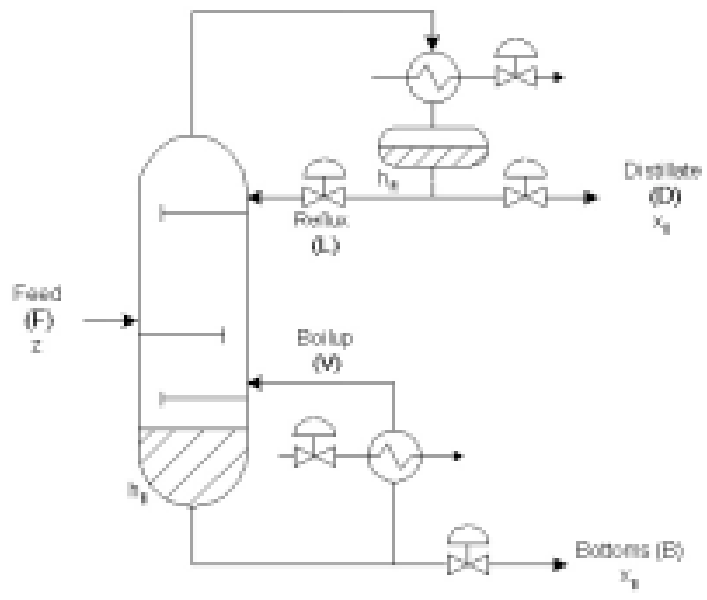

Fig. 5. Basic Distillation Column. 
Ratio control of the simple system illustrated in Figure 4 is also studied to show that it is effective for low frequency disturbances.

\subsection{Workshop 7 - Distillation Control}

Distillation is one of the most important single unit operations in chemical engineering and as such it forms the basis of many processes and is an essential part of many others. It presents a more difficult control problem compared with many other unit operations as at least five variables need to be controlled simultaneously and there are at least five variables available for manipulation, as can be seen in Figure 5, a basic distillation column. Thus a distillation column provides an example of a multiple-input multiple-output (MIMO) control problem. It is critical that variable pairing is done appropriately between controlled and manipulated variables. The overall control problem can usually be reduced to a $2 \times 2$ composition control problem, e.g. LV, DV or LB control (Shinskey, [18]) since the inventory and pressure loops frequently do not interact with the composition loops. This workshop highlights some fundamental rules of distillation control and shows how a basic distillation control scheme can be selected using steady state analysis (Fruehauf and Mahoney, [19]) and dynamic simulation to evaluate the effectiveness of selected control schemes.

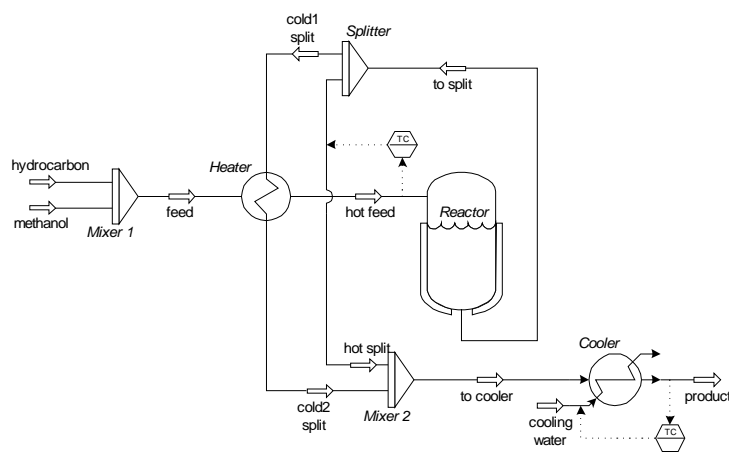

Fig 6. MTBE Reaction System with Heat Integration.

\subsection{Workshop 8 - Plant Operability and \\ Controllability}

Traditionally, process design has been performed using steady state analysis only. Simple rules of thumb have been used to size vessel hold-ups and to set other variables that affect the dynamic performance of a plant. This can sometimes lead to operability and controllability problems as a design might look good in the steady state but be very difficult to operate or control due to the presence of dead times or insufficient capacitance.

A key consideration for plant operability and controllability is variable interaction. The students have learned that dead time is one of their enemies as it always makes tight control more difficult to achieve. Variable interaction places similar restrictions on the control of a process and can significantly reduce the overall control system performance. Three common sources of variable interaction are the nature of the process (i.e. distillation), the combination of multiple unit operations and heat integration. Each of these points can be highly advantageous in the steady state but can also create operability and controllability problems that may not be evident without considering the process dynamics at the design phase.

This workshop investigates two major examples where variable interaction is significant, namely two-point distillation composition control (Ryskamp, [20]) and the control of the MethylTert-Butyl Ether (MTBE) exothermic reaction system with heat integration as shown in Figure 6. The workshop also introduces the relative gain array technique (Bristol, [21]) for finding the best variable pairings in MIMO systems. The potential trade-off between capital savings and plant operability is also demonstrated.

In line with the open-ended nature of the desigr process and the "hands-on" philosophy of the course, the problems in this workshop are more open-ended than other workshops. The students are encouraged to work more freely and continue their analysis until they are satisfied that they have pursued all paths.

\subsection{Final Workshop/Course Assessment}

It is also recommended that the final assessment or exam task be a workshop type problem such as the control of a separator such as shown in Figure 1. This is considered to be fair since the hands-on workshops consist of the majority of the insemester assessment and it helps motivate the students to do the workshops well.

\section{Evaluation}

The real time workshop approach to process education was first developed in 1996 as a set of workshops and an associated text. This version was used at the University of Calgary during the 1997 academic year as a pilot course for nine students as their senior year controls course. Their 
comments were used and motivated a revised second version of the workshops and the notes. This second version was used as a basis for the classes of 1998, 1999 and 2000 at the University of Calgary, totaling forty-five, sixty and eighty students, respectively. A further revision was published in 2000 (Svrcek et al., [7]) and used since 2001.

As a means of generating feedback, the students were asked to complete a questionnaire on the "hands-on real time workshop approach". Overall, the overwhelming majority of students enjoyed the "hands-on real time workshop approach" to learning process control. More than $80 \%$ of the students said the approach was clear, concise, useful and applicable. The major complaints, from a minority of students, were that they did not like "hands-on" self directed learning, found the workshops too involved and time consuming and would have preferred a standard course consisting of lectures, assignments, quizzes and a written final exam.

\section{Conclusions}

A "hands-on" real time simulation approach to undergraduate process control education in chemical engineering with the aid of realistic workshops involving real time simulation of chemical processes was presented. The workshops are based on fundamental process models of industrial unit operations using educationally affordable and readily available commercial process simulation software.

Student feedback from seven years of implementation at the University of Calgary evaluated the integrated "hands-on" real time simulation workshop approach as effective, useful and applicable.

\section{Acknowledgments}

The authors acknowledge the support of the many undergraduate and graduate students from the University of Calgary who have helped with the development of the integrated, real-time approach to process control system design education since 1996.

\section{References}

[1]. Downs, J.J. and J.E. Doss, "Present Status and Future Needs: A View from North American Industry", in Proceedings of Chemical Process
Control IV, Arkun, Y. and W.H. Ray, (Eds.), AIChE, New York, NY, 1991

[2]. Ramaker, B.L., H.K. Lau and E. Hernandez, "Control Technology Challenges for the Future", in Proceedings of Chemical Process Control V, Tahoe City, CA, 1996, AIChE Symposium Series No. 316, 93, 1, 1997

[3]. Svrcek, W.Y., D.P. Mahoney and B.R. Young, "A Real-time Approach to Process Control", John Wiley and Sons, Ltd., Chichester, England, 326p, 2000

[4]. Young, B.R., D.P. Mahoney and W.Y. Svrcek, "A Real-time Approach to Process Control Education", Chem. Eng. Ed., 2000

[5]. Litster, J.D., R.B. Newell and P.L. Lee, "Resource Based Education for Training Chemical Engineers", Chem. Eng. in Australia, 15 (2), 1990

[6]. Cough, D.E., "Bringing Active Learning into the Traditional Classroom: Teaching Process Control the Right Way", ASEE Annual Conf., Seattle, WA, 1998

[7]. Young, B.R., D.P. Mahoney and B.R. Young, "Real-time Computer Simulation Workshops for the Process Control Education of Undergraduate Chemical Engineers", Computers in Engineering Education, January 2001, pp57-62

[8]. Svrcek, W.Y., W.D. Sim, and M.A. Satyro. (1996). From Large Computers and Small Solutions to Small Computers and Large Solutions, Proceedings of CHEMECA'96, the $24^{\text {th }}$ Australian and New Zealana Chemical Engineering Conference, Sydney, Australia, 2, pp. 11-18.

[9]. Franks, R.G.E. (1972). Modelling and Simulation in Chemical Engineering. John Wiley and Sons, New York.

[10]. Ausain, A. (1986). Chemical Process Simulation. John Wiley and Sons, New York, pp.201-206.

[11]. Perkins, J.D. (1986). Survey of Existing Systems for the Dynamic Simulation of Industrial Processes. Modelling, Identification and Control, 7 (2), April, pp. 71-81.

[12]. HYSYS. (1998). HYSYS.Process, Version 1.5.2, AEA Technology Engineering Software, Hyprotech Ltd., Calgary, Alberta, Canada.

[13]. Aspen Dynamics. (2000). Aspen Dynamics, Version 10.1, Aspen Technology, Inc. Cambridge, MA.

[14]. MATLAB. (2000). MATLAB, Version 5.3.1, The MathWorks, Inc., Natick, MA.

[15]. White, S.R. and G.R. Bodner. (1999). Evaluation of Computer-Simulation Experiments in a SeniorLevel Capstone ChE Course, Chemical Engineering Education, winter quarter, pp. 34-39.

[16]. Ziegler, J.G. and N.B. Nichols. (1942). Optimum Settings for Automatic Controllers, Trans. ASME, 64, pp.759-768.

[17]. Åström, K.J. and T. Hagglund. (1984). Automatic Tuning of Simple Regulators with Specifications on Phase and Amplified Margins, Automatica, 20 (5), pp. 645-651. 
[18]. Shinskey, F.G. (1984). Distillation Control for Productivity and Energy Conservation, ( ${ }^{\text {nd }}$ Ed.), McGraw-Hill Inc., New York.

[19]. Freuhauf, P.S. and D.P. Mahoney. (1992). Distillation Column Control and Design Using Steady State Models: Usefulness and Limitations, Proceedings of ISA'92, Instrument Society of America Conference, Paper \# 92-0279, pp. 93-120.
[20]. Ryskamp, C.J. (1980). New Strategy Improves Dual Composition Control (also effective on thermally coupled columns), Hydrocarbon Processing, June, pp. 51-59.

[21]. Bristol, E.H. (1966). On a New Measure of Interactions for Multivariable Process Control, IEEE Trans. Auto. Con., AC-11, pp. 133-134. 